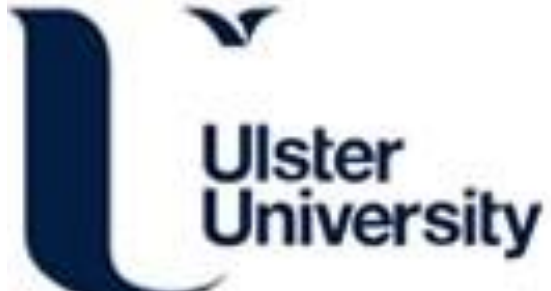

\section{An investigation into the usability of the STAR training and re-skilling website for carers of persons with dementia}

Boyd, K., Nugent, C., Donnelly, M., Bond, RR., Sterritt, R., \& Hartin, P. (Accepted/In press). An investigation into the usability of the STAR training and re-skilling website for carers of persons with dementia. In Unknown Host Publication (pp. 4139-4142). IEEE. https://doi.org/10.1109/EMBC.2014.6944535

Link to publication record in Ulster University Research Portal

\author{
Published in: \\ Unknown Host Publication
}

\section{Publication Status:}

Accepted/In press: 06/05/2014

DOI:

10.1109/EMBC.2014.6944535

\section{Document Version}

Publisher's PDF, also known as Version of record

\section{General rights}

Copyright for the publications made accessible via Ulster University's Research Portal is retained by the author(s) and / or other copyright owners and it is a condition of accessing these publications that users recognise and abide by the legal requirements associated with these rights.

\section{Take down policy}

The Research Portal is Ulster University's institutional repository that provides access to Ulster's research outputs. Every effort has been made to ensure that content in the Research Portal does not infringe any person's rights, or applicable UK laws. If you discover content in the Research Portal that you believe breaches copyright or violates any law, please contact pure-support@ulster.ac.uk. 


\title{
An Investigation into the Usability of the STAR Training and Re-skilling Website for Carers of Persons with Dementia
}

\author{
Kyle Boyd, Chris Nugent, IEEE Member, Mark Donnelly, Raymond Bond, Roy Sterritt and Phillip \\ Hartin
}

\begin{abstract}
Due to the successes in medical science people are now beginning to live much longer. With this brings increased problems associated with ageing, with one exemplar being dementia. Persons with dementia require care with activities of daily living, for example, with washing, dressing and eating. This requires additional care, which is usually provided by family and friends who assume the role of informal carers. Provision of care by informal carers brings irreversible changes to their lives that can lead to depression and feelings of loneliness. In part, these changes are linked with carers having insufficient understanding and training with dementia. The EU funded STAR project created an web portal that aims to provide the necessary online training that carers need, however, the usability of such a provision warrants investigation. This paper presents the findings of a usability test conducted on five carers of people with dementia while using the STAR Training Website. For the 21 usability issues identified, the paper outlines proposed solutions.
\end{abstract}

\section{INTRODUCTION}

By 2050, 2 billion people in the world will be 60 years old [1]. Associated with ageing brings debilitating conditions such as Chronic obstructive pulmonary disease (COPD) and dementia. Symptoms of dementia include impairments of memory, thought, perception, speech and reasoning and can leave people incapable of completing simple tasks independently[2]. Many people with dementia require the support from carers to help with these tasks like washing, eating and dressing. Moreover, 52\% of carers are not obtaining the help they need for their own daily lives, with two-thirds missing out on medical help themselves as a result of providing care for someone else[3]. Additionally, carers of persons with dementia (PwD) typically suffer from periods of depression, feelings of isolation and loneliness[4, 5]. Ultimately, they also need educated into how to properly provide care for persons with dementia.

One manner in which carers may be educated is through the delivery of appropriate online training material. This paper describes the results from a usability test conducted on an online platform for delivery of training material for carers of people with dementia. The goals of usability testing include establishing a baseline of user performance, identifying and validating user performance measures and pointing out potential design concerns that need to be

STAR is funded by a EU Lifelong Learning Project 51034. Kyle Boyd, Chris Nugent, Mark Donnelly, Raymond Bond, Roy Sterritt and Philip Hartin are with the Computer Science Research Institute and the School of Computing and Mathematics, University of Ulster. Email at the following addresses: boyd-k5, Hartin-P1@email.ulster.ac.uk and cd.nugent, mp.donnelly,rb.bond,r.sterritt@ulster.ac.uk. addressed in order to improve the efficiency, productivity and end-user satisfaction. Section II discusses the STAR project and the background to the project in more detail.

\section{THE STAR PROJECT}

Online services that provide strategies to inform and deliver enhanced skills and understanding for carers of PwD can provide an effective assistive technology that can lead to better healthcare delivery. The European STAR[6] project provides those caring for PwD (both formal and informal) with online training to better understand the disease and how to provide better care. The STAR Project created an educational platform with an associated methodology and clinically validated content for improving the skills of carers for PwD. The content was based on leading dementia expertise and was distributed in a three-layer online community structure. New technology-based interventions for monitoring and supporting persons with dementia were covered in the educational modules as a core focus. This approach enabled skilling and re-skilling for appropriate professional care for persons with mild dementia, even when living in their homes and with their family. The low technical capability of end users means that the usability assessment of user interfaces and the user experience is warranted.

\section{METHODOLOGY}

A description of the methodology adopted to undertake the usability study is presented below. This includes details of who conducted the test, which subjects were tested, the metrics collected and how the results will be disseminated. The aim is to evaluating the effectiveness of ICT based training materials for supporting care home environments for carers with caring responsibilities and tenants in care homes to maintain a healthy mind. To use the ICT based training materials under controlled test conditions with representative users. The objectives are: To discover usability issues of various ICT based training materials. To gain an insight into the usability issues of carers over a number of age ranges and experience levels and establish a set of solutions to remove use errors and improve the user experience.

\section{A. Participants}

According to Nielsen[7], 85\% of usability problems can be found when testing a system with five users. Consequently, the study recruited five participants ( 2 males aged 44 and 32 and 3 females aged 46, 47 and 56, respectively [mean age = 45]). All participants were informal carers of PwD. The general caring responsibilities of the participants were associated with activities of daily living; washing, dressing, 
preparing meals and transporting them to hospital appointments were the most common. Two of the participants were employed, two were retired and one was in education. In assessing their level of computer literacy using a scale of 1-7, with 1 being novice and 7 being expert, the mean response from the participants was 3.20 indicating that participants had a basic operating knowledge of computers. Moreover, 4/5 participants said that they found a learning new computer skill was not difficult.

\section{B. Procedure}

Participants conducted the usability test at Innisoole Day Centre at Rathcoole in Belfast, Northern Ireland.

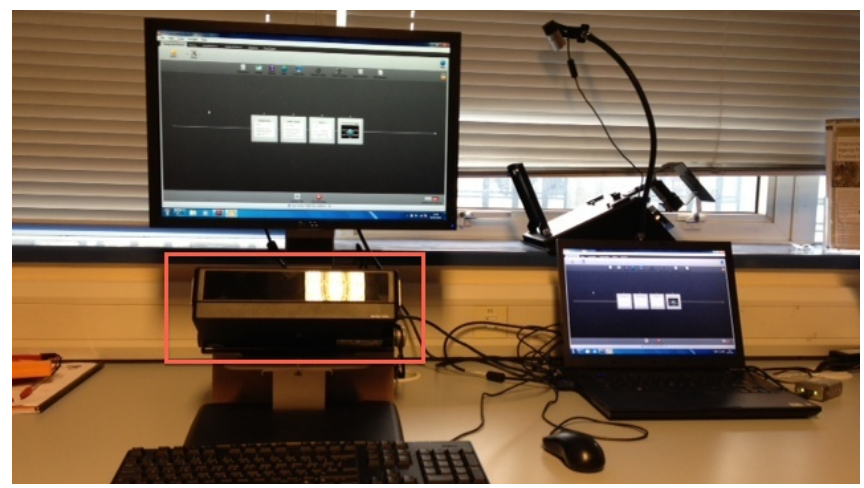

Figure 1. The Tobii X60 Eyetracker highlighted in the red box.

Participants were asked to use a Windows PC with a Tobii X60 Eyetracker when using the STAR training material. The Eyetracker uses infrared technologies to determine where people are looking on a screen. It records fixations (where an eye is focused) and saccades (movements between fixations), which are used to create heat and gaze maps[8]. The eyetracker records these and are used to determine usability issues[9]. From the heat and gaze maps it can determine whether participants were looking at appropriate objects, differentiate between reading and scanning words, learn the relative intensity of the user's attention to various parts of the interface, and find out whether the user was seeing specific items. The investigator and the participant were both stationed in the same office to allow the investigator to monitor the participant's interactions with the Web site.

\section{The Usability Tasks Undertaken}

The usability tasks were derived from tasks which were deemed to meet the core use of the website. Due to the range and extent of functionality provided in the Web site, and the short time for which each participant was available (around 30 minutes), the tasks selected were the most common and relatively complex of all the available tasks. The selected tasks were identical for all participants in the study. Each task was administered to the participants both verbally and in written format. The tasks completed are presented in Table I.

TABLE I. ThE TASKS ATtEMPTED BY THE PARTICIPANTS

\begin{tabular}{|l|l|}
\hline Tasks & Tasks Attempted \\
\hline 1 & Talk about the home page \\
\hline 2 & Find the Learning paths of the training \\
\hline
\end{tabular}

\begin{tabular}{|l|l|}
\hline 3 & Complete course material - what is dementia? \\
\hline 4 & Take Module quiz and \\
\hline 5 & Take Knowledge quiz \\
\hline 6 & Find the 'Getting a diagnosis' module \\
\hline 7 & Find YouTube Videos \\
\hline 8 & Read latest news article \\
\hline
\end{tabular}

\section{USABILITY GOALS}

Usability goals refer to user performance measured to satisfy usability requirements. Task completion success rates, error rates and subjective evaluations and time-tocompletion of tasks were subsequently collected.

\section{A. Completion Rate}

Completion rate is the percentage of test participants who successfully completed the task without critical errors. A critical error is defined as an error that results in an incorrect or incomplete outcome. In other words, the completion rate represents the percentage of participants who, when they are finished with the specified task, have an "output" that is correct. If a participant requires assistance in order to achieve a correct output then the task will be scored as a critical error and the overall completion rate for the task will be affected.

TABLE II. PERCENTAGE OF TASKS COMPLETED BY PARTICIPANTS

\begin{tabular}{|l|l|l|l|}
\hline $\begin{array}{l}\text { Tasks (Details } \\
\text { in Table I. }\end{array}$ & \multicolumn{2}{|l|}{$\begin{array}{l}\text { How many participants } \\
\text { completed each task }\end{array}$} & \\
\hline 1 & 5 & $100.00 \%$ & 0.8571 \\
\hline 2 & 4 & $80.00 \%$ & 0.7143 \\
\hline 3 & 4 & $80.00 \%$ & 0.7143 \\
\hline 4 & 0 & $0.00 \%$ & 0.1429 \\
\hline 5 & 3 & $60.00 \%$ & 0.5714 \\
\hline 6 & 5 & $100.00 \%$ & 0.8571 \\
\hline 7 & 3 & $60.00 \%$ & 0.5714 \\
\hline 8 & 1 & $20.00 \%$ & 0.2857 \\
\hline
\end{tabular}

Of all the tasks 3 of participants were able to complete half or more of the tasks and 4 could complete training course, games and knowledge quiz.

\section{B. Efficiency}

The time to complete a scenario is referred to as "time on task". It is measured from the time the person begins the scenario to the time they signal completion. Time on task is shown by each participant in Figure 2.

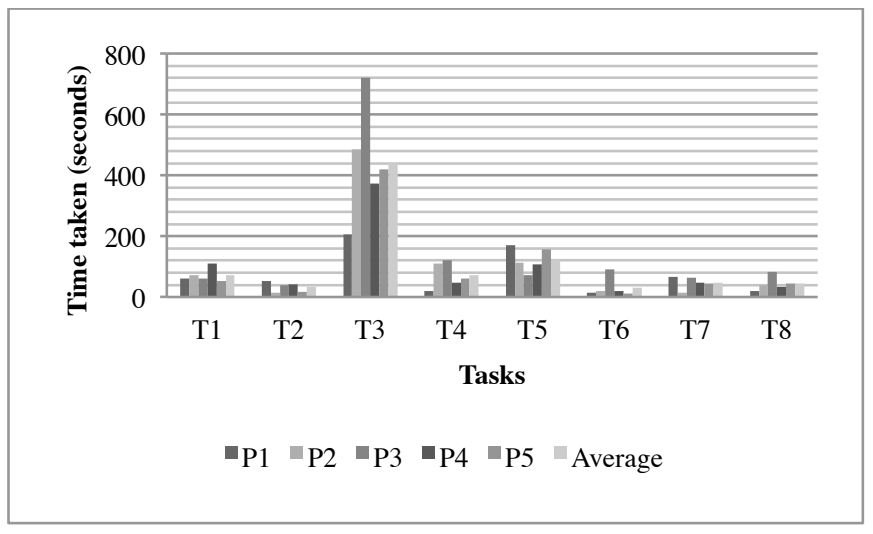

Figure 2. Time taken by each participant to complete task 


\section{Usability Issues}

To prioritize which usability issues should be addressed first and last, a method of problem severity classification was used[10]. The approach treats problem severity as a combination of two factors - the impact of the problem and the frequency of users experiencing the problem during the evaluation in addition to the heuristic value, which has been compromised. The 10 most general principles for interaction design[11] are called "heuristics" these include:

1. Visibility of system status

2. Match between system and real world

3. User control and freedom

4. Consistency and standards

5. Error prevention

6. Recognition rather than recall

7. Flexibility and efficiency of use

8. Aesthetic and minimalist design

9. Help user to recognize and recover from errors

10. Help documentation

Each issue was matched to whichever heuristic value had been infringed (to check the web pages compliance with the heuristic values) along with a severity rating. These are[10]:

1. Critical: Usability catastrophe: imperative to fix this before product can be released (critical error)

2. Serious:Major usability problem: important to fix, so should be given high priority (critical error)

3. Medium: Minor usability problem: fixing this should be given low priority (non-critical error)

4. Low: Cosmetic problem only: need not be fixed unless extra time is available on Project (noncritical error)

After analysing recordings and observing each of the participant's actions, a total of 21 issues were identified. Five issues were categorized as serious and two issues were deemed as being critical. Serious and critical issues are presented in Table III along with frequency of occurrence $(f)$, heuristic value infringed $(h v)$ and severity rating $(s r)$. A solution to each issue is also provided.

TABLE III. MOST SEVERE USABILITY ISSUES FOUND DURING TEST AND SOLUTIONS OF HOW TO ADDRESS THESE ISSUES

\begin{tabular}{|c|c|c|c|c|}
\hline $\begin{array}{c}\text { Issue } \\
\text { Number }\end{array}$ & Description of Usability Issue & $(f)$ & (hv) & $(s r)$ \\
\hline 1 & Couldn't find search bar to look for words & 4 & 6 & 4 \\
\hline Solution & \multicolumn{4}{|c|}{ Make tools bigger and clearer and include a search bar on website } \\
\hline 2 & $\begin{array}{l}\text { Never went back to the home page - home link not } \\
\text { visible in footer and hard to find on top }\end{array}$ & 4 & 6 & 4 \\
\hline Solution & \multicolumn{4}{|l|}{ Use 'Home' instead of home icon } \\
\hline 3 & $\begin{array}{l}\text { There is a lot of text on each window - might be } \\
\text { difficult for those to read on screen }\end{array}$ & 1 & 8 & 3 \\
\hline Solution & \multicolumn{4}{|c|}{$\begin{array}{l}\text { Decrease amount of text on screen or format to include more line } \\
\text { breaks include a text resizer. }\end{array}$} \\
\hline 4 & $\begin{array}{l}\text { To play videos participants didn't know whether to } \\
\text { click the icon or the text }\end{array}$ & 1 & 7 & 3 \\
\hline Solution & \multicolumn{4}{|c|}{ Remove underline from text and include one button 'Play Video' } \\
\hline
\end{tabular}

\begin{tabular}{|c|l|c|c|c|}
\hline 5 & $\begin{array}{l}\text { Couldn't get back to the home page because the } \\
\text { courses opened in a new window }\end{array}$ & 1 & 1 & 3 \\
\hline Solution & Load videos within website layout \\
\hline 6 & $\begin{array}{l}\text { Found difficult to locate the next button and quiz } \\
\text { button }\end{array}$ & 4 & 6 & 3 \\
\hline Solution & Make these buttons bigger & $\begin{array}{l}\text { YouTube videos load in a new window - if closed } \\
\text { lose position and can't find way back }\end{array}$ & 1 & 7 \\
\hline Solution & Load videos within website layout & 3 \\
\hline
\end{tabular}

\section{Subjective Measures}

Subjective opinions about specific tasks, time to perform each task, features and functionality were surveyed. At the end of the test, participants rated their thoughts on usefulness, ease of use, ease of learning and satisfaction with the overall system. These questions are presented after the test, this data is used to assess attitudes of the participants.

\section{RESULTS}

To ensure coherency, the results of the usability test have been presented in the previous section along with the methods. It is our intention to discuss these findings and address the main usability issues with a series of solutions.

\section{A. Completion Rates}

From all the tasks $60 \%$ of participants were able to complete half or more of the tasks and $80 \%$ could complete training course, games and knowledge quiz. No one could find the page guide on task 4 and gave up trying to complete this task, hence the shorter elapsed time shown.

\section{B. Efficiency}

The efficiency of each task was recorded for each participant. Tasks 2, 6, 7 and 8 all recorded similar times. These tasks required similar interactions and show that navigation around the site can be completed on average between 30-40 seconds. This is positive for first time novice users. The time would decrease as the layout and interaction patterns would be learnt through usage. Task 3 took the longest because it required participants to complete a module. On average it took 7.4 minutes to complete. Four participants completed this task. This is considered as being the core purpose of the STAR website. Completion time is not as important as their ability to complete it.

\section{Satisfaction}

The satisfaction of the website was measured from a posttest questionnaire which was given to participants after the tasks had been completed. All participants (100\%) agreed that the STAR website was useful, that it was easy to learn how to use it and that they would recommend it to a friend or colleague. From the responses, 4 of the 5 participants indicated that they were satisfied with the website and 3 of 5 responses found that it was pleasant to use. Only 2 out of 5 found it easy to use and only 1 participant found it easy to recover from mistakes. This correlates with usability issue 2. When participants became lost they could not locate the home button to 'get back to the start'. Only 2 out of 5 thought it was fun to use. The carers did not really want to be in the position of using the website as some stated "If my 
parents didn't have dementia then I wouldn't need this and that would be so much better".

\section{Usability Issue Solutions}

Twenty-one usability issues were identified. Solutions to the most serious, critical and frequent problems are presented in Table III and with the issues and solutions in Figure 3. These included using text instead of icons for navigation, enabling web pages load in the current window as opposed to a new window, larger body text throughout as at times participants found the text illegible.
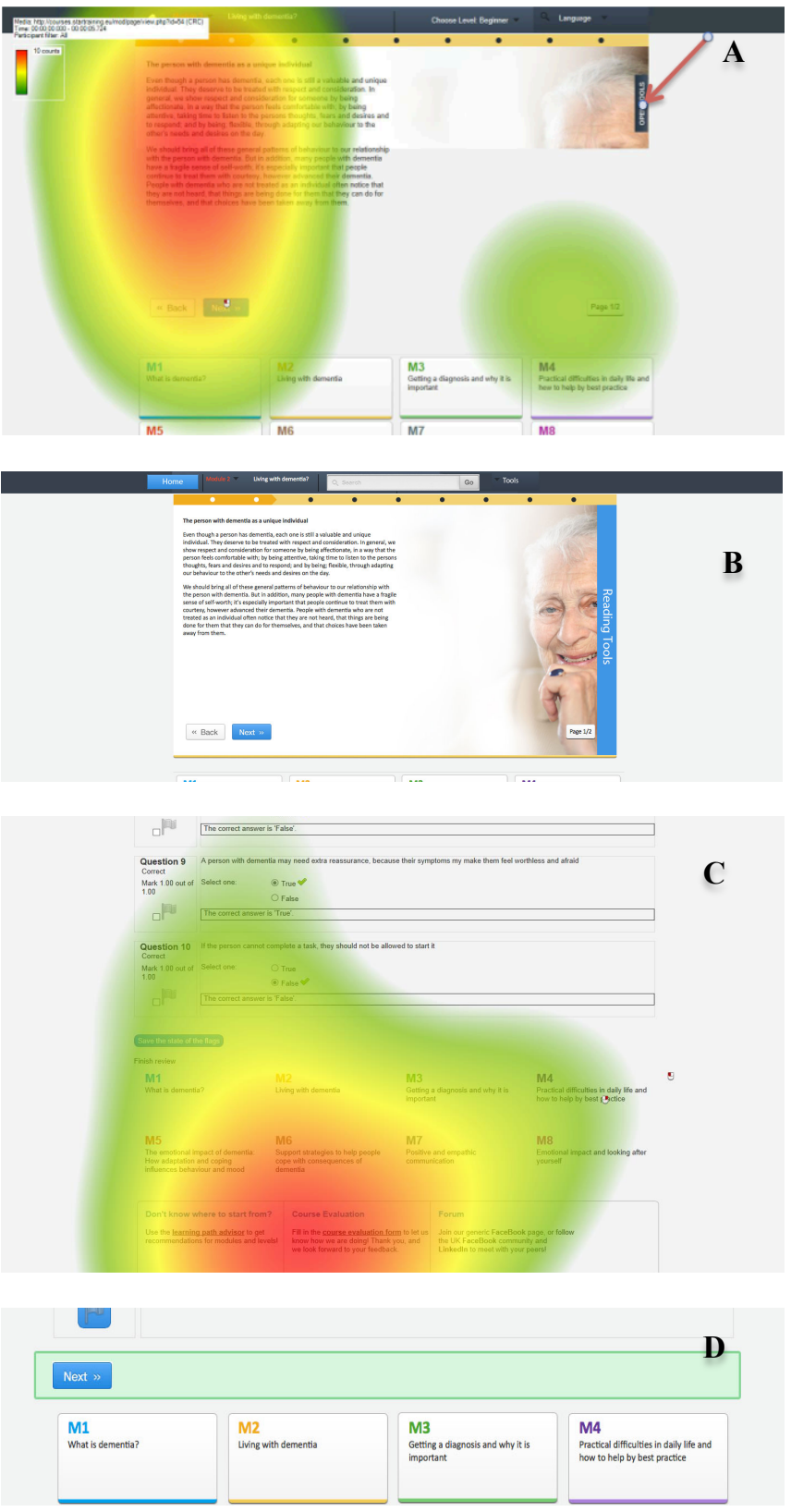

Figure 3. A. Heatmap shows that participants are seeing main body text and the page numbers but are not picking up the tools button which is

indicated by the red arrow. B. A solution to the problem shown in A is to add bigger buttons with better coverage. $\mathrm{C}$. This heatmap shows that

participants are looking in the area of the button but because of its size they are not picking this up and going striaght to the bottom menu. D. A solution to the issue in figure $\mathrm{C}$ is to use bigger buttons and in a visual container which highlights the clickable button.
Loading YouTube videos in the current website was also an issue because the web page for viewing them opens up in new browser windows. For issues 1 and 6, heat maps have been generated from the eyetracker to show why the issues occurred. These are shown in Figures 3A and 3C. Visual solutions as shown in Figures 3B and 3D have been created to show that the issues can be remedied. Participants found it difficult to find a number of buttons because of their size and color; this is shown in Figure 3C. A solution is to make buttons bigger and place these in a visual container or clarity; this is shown in Figure 3D. These solutions should make a big difference to the usability and user experience of the project website.

\section{CONCLUSION}

This paper details the results following a usability test on the STAR training website. The STAR project has created an educational platform with associated methodology and content for improving the skills of carers for People with dementia. The paper presents a methodology detailing how the usability test was completed, results from the test, analysis of the efficiency, user satisfaction and the usability errors that occurred during the tests. Solutions to the most critical errors were also provided. All participants demonstrated the ability to navigate the website to a reasonable standard. Participants were also quite satisfied with the website content, games and quizzes. Nevertheless, the usability testing uncovered 21 issues. These are mainly categorized under interaction problems due to poor layout and presentation making recovering from mistakes more difficult. Feedback from the usability test have been integrated into new releases of the STAR training platform.

\section{ACKNOWLEDGMENT}

Boyd et al. wish to thank all staff and carers from Inniscoole day centre who facilitated the usability test.

\section{REFERENCES}

[1] Alzheimers Assoc.Facts and figures of Alzheimer's Disease. 2012.

[2] Alzheimer's Disease International, "World alzheimer report," 2011.

[3] Princess Royal Trust for Carers, "'Always on call, always concerned: A surveyof the experiences of older carers'," 2011.

[4] R. Mahoney, C. Regan, C. Katona and G. Livingston, "Anxiety and depression in family caregivers of people with Alzheimer disease: the LASER-AD study," The American Journal of Geriatric Psychiatry, vol. 13, pp. 795-801, 2005.

[5] C. Cooper, T. Balamurali and G. Livingston, "A systematic review of the prevalence and covariates of anxiety in caregivers of people with dementia," International Psychogeriatrics, vol. 19, pp. 175-195, 2007.

[6] Star Project. 3/4/2014 http://startraining.eu/index.php/en/.

[7]J. Nielsen. Why you only need to test with 5 users. http://goo.gl/oK1EbJ Accessed: 09/06/14

[8] J. Nielsen, K. Pernice, Eyetracking Web Usability. Newriders, 2010. [9] S. Krug, Don'T make Me Think! A Common Sense Approach to Web Usability. Berkley: Newriders, 2009.

[10] J. Nielsen, "Severity ratings for usability problems," Papers and Essays, 1995.

[11] J. Nielsen and J. T. Hackos, Usability Engineering. Academic press Boston, 1993. 